\title{
MORPHOLOGICAL AND MICROSTRUCTURAL CHARACTERIZATION OF LASER-GLAZED PLASMA-SPRAYED THERMAL BARRIER COATINGS
}

\author{
C. Batista ${ }^{a}$, A. Portinha ${ }^{a}$, R. M. Ribeiro ${ }^{a} *$, V. Teixeira ${ }^{a}$, M. F. Costa ${ }^{a}$ and C. R. Oliveira ${ }^{b}$ \\ ${ }^{a}$ University of Minho, Physics Department, Campus de Gualtar, 4710-057 Braga, Portugal \\ ${ }^{b}$ IDIT - Instituto de Desenvolvimento Inovação Tecnológica, 4520-102 Santa Maria da Feira, Portugal and University \\ Lusíada, 4760-108 Vila Nova de Famalicão, Portugal
}

\begin{abstract}
Laser-glazing has been revealing a high potential for the improvement of plasma-sprayed (PS) thermal barrier coatings (TBCs) by reducing surface roughness, eliminating open porosity on the surface and generating a controlled segmented crack network, although the relationship of the processing parameters with the resultant properties has not yet been completely established. In this investigation, TBCs consisting of atmospheric plasma sprayed (APS) $\mathrm{ZrO}_{2}-8 \%$ wtY $\mathrm{O}_{3}$ were subjected to a $\mathrm{CO}_{2}$ continuous wave laser glazing process in order to seal its surface porosity generating an external dense layer. For that purpose, different amounts of radiation resulting from different scanning speeds were applied to the specimens as well as different track overlapping. Results have shown a significant decrease of the surface roughness after the laser treatment. All specimens presented a fully dense and porous free external layer with a polyfaceted columnar microstructure highly adherent to the plasma-sprayed coating. Controlled surface crack networks, extremely dependent on the laser scanning speed and track overlapping, were achieved for each set of processing parameters. The cracks were found to have a tendency to be oriented in two perpendicular directions, one in the direction of the laser beam travel direction, the other perpendicular to it. Moreover, the cracks parallel to the beam moving direction are found to be on the overlapping zone, coinciding with the edge of the subsequent track. The cracks are perpendicular to the surface along the densified layer and tend to branch and deviate from the vertical direction below it, within the porous PS coating. XRD results revealed mainly t' non-transformable tetragonal zirconia with a small percentage of residual monoclinic zirconia for the as-sprayed coating. All glazed coatings presented only t' non-transformable tetragonal zirconia with some variations on preferable crystal orientation. Grain sizes varied from 26 to $52 \mathrm{~nm}$, increasing with an increase of laser irradiated energy, microstrain behaved inversely.
\end{abstract}

Keywords: Characterization; Thermal Barrier Coatings; Laser Glazing; Zirconia; Plasma Spraying

* Corresponding author. Tel.: +351-253 604 335; Fax: +351-253 678981.

Address: University of Minho, Physics Department, Campus de Gualtar, 4710-057 Braga, Portugal

E-mail address: ricardo@ fisica.uminho.pt (R. M. Ribeiro) 


\section{Introduction}

Thermal barrier coatings (TBCs) have successfully entered service in the turbine section of advanced gas turbine engines in the mid-1970s [1]. Since then, several improvements on the selected materials, processing techniques and life prediction tools have been taking place to contribute for the improvement of TBC's performance as well as for the widening of the field of applications.

Current thermal barrier coating systems consist of a bond coat deposited over the material to be protected and then the TBC itself is applied to the bond coat. The metallic bond coat (MCrAlY, $\mathrm{M}=\mathrm{Ni}, \mathrm{Cr}$ or $\mathrm{Ni} / \mathrm{Cr}$ ) acts as a corrosion resistant layer to protect the substrate material (Nickel-based superalloy), forming alumina as the principal protective scale (thermally grown oxide (TGO)). Due to mismatch of thermoelastic properties between the metallic substrate and the ceramic top coat, the bond coat is also necessary to accommodate residual stresses avoiding its development along the coating system. MCrAlY coatings may be applied by a variety of techniques where the most frequent are vacuum plasma spraying (VPS) and low pressure plasma spraying (LPPS). The top coat most commonly applied material is yttria partially stabilized zirconia (YPSZ) which has very low thermal conductivity, high thermal expansion for a ceramic material, high chemical stability, and reasonable resistance to thermal shock and thermal fatigue at high temperatures. It may be deposited either by electron beam physical vapour deposition (EBPVD) or more frequently by atmospheric plasma-spraying (APS).

During the plasma-spraying process, residual stresses within the coating system are generated by the rapid cooling of molten droplets and are relieved by through-thickness microcracking [2]. The presence of segmented cracks and interconnected porosity due to volume shrinkage and residual stresses in the top coat [2-7] affects the mechanical properties and deteriorates the oxidation and corrosion resistance. These features are considered to be the path for molten salts and corrosive gases to attack the TBC system, especially in applications where low purity fuels are burned. Furthermore, the infiltration of oxygen through the top coat leads to an increase in thickness of the TGO, favouring spallation when the critical level is reached.

Previous studies have reported a variety of methods for sealing TBC's top coat surface porosity, including laser-glazing. None of these procedures has yet come into common use, possibly due to the few applications of TBCs in engine sections where corrosive deposits are developed [8].

Laser-glazing has been revealing a high potential for the improvement of plasma-sprayed TBCs properties by reducing surface roughness, eliminating open porosity on the surface and generating a controlled segmented crack network.

Previous investigations [9] showed that regardless a non evident effect on reducing the oxidation rate of the bond coat, the thermal cyclic lifetimes of plasma-sprayed TBCs were enhanced about fourfold by improving the strain accommodation through segmented cracks by laser-glazing. Recently, P.C. Tsai et al. [10] verified an enhancement of also approximately fourfold in the lifetimes of plasma-sprayed TBCs by laser-glazing in high temperature corrosion tests involving $\mathrm{V}_{2} \mathrm{O}_{5}$ salts. Latest studies [11] have shown that laser-glazing $\mathrm{ZrO}_{2}-8 \%$ wt $\mathrm{Y}_{2} \mathrm{O}_{3}$ coatings improved considerably microhardness, erosion and abrasion resistance, whilst lowered strength and stiffness.

Cracks, perpendicular to the surface along the densified layer are characteristic features of laser melted ceramic materials [5,6,9-21] and are generated by shrinkage and relief of thermal-induced stresses $[9,16,20,22]$. It was shown that these cracks, induced by laser treatment, improved thermal shock resistance. Moreover a considerable reduction on the surface roughness leads to an improvement of the erosion resistance. On the other hand, microstructural modification, from lamellar to columnar can alter heat transfer by increasing thermal conductivity. Also, the existence of macroscopic vertical cracks may provide a fast path for oxygen and molten salts to attack the TBC system. For all these reasons, several studies have been carried out and are still underway to accomplish an affordable compromise between the desirable and undesirable properties.

In this work the effect of the laser-glazing process parameters on the surface morphology, microstructure and phase transformation of the $\mathrm{ZrO}_{2}-8 \% \mathrm{wtY} \mathrm{O}_{3}$ coatings is discussed. Thicknesses of the densified layers and distribution of the characteristic laser-induced cracks are investigated. 


\section{Experimental details}

\subsection{Material}

For the purpose of this work, steel plates were used as substrates and no bond coat has been applied. The thermal barrier coatings consisted of $\mathrm{ZrO} 2-8 \mathrm{wt} \% \mathrm{Y}_{2} \mathrm{O}_{3}$ deposited by atmospheric plasma-spraying (APS). Specimen preparation details are described elsewhere [23].

\subsection{Laser-glazing}

The laser-glazing process was accomplished with an industrial high power $(6.0 \mathrm{~kW}) \mathrm{CO}_{2}$ continuous wave laser (wavelength $10.6 \mu \mathrm{m}$ ) (Rofin-Sinar RS6000) with a 3-axis CNC workstation. Laser system characteristics and chosen processing parameters are presented in Table 1. Different scanning speeds (moving specimen on the CNC table), shown in Table 2, were set to apply different amounts of energy to each sample. The laser was operated in a $\mathrm{TEM}_{01 *}$ mode at the chosen power, and with the beam slightly defocused. Another sample was used before the final glazing process to generate a single track at each chosen scanning speed. The width of each track was then measured so the beam could be shifted away a sufficient distance for each parallel scan assuring a known overlap of tracks. The laser beam guiding is represented in Fig. 1.

\subsection{Characterization}

\section{Morphology and microstructure}

Coating microstructures and surface morphologies were analyzed by optical and scanning electron microscopy (SEM) (Leica Cambridge S360). Cross-section planes, perpendicular to laser beam travel, were previously prepared metallographically for cross-section analysis. Free-standing coatings were prepared as well so they could be fractured and observed along through-thickness. Specimens with single tracks were also sectioned and polished followed by optical microscopy examination in order to measure the track depths.

As a complementary technique to monitor morphological changes on the coatings surface and to determine roughness for each coating, an optical triangulation method has also been used [24]. For this purpose, due to surface transparency of the glazed coatings, specimens were previously sputter-coated with an opaque thin film.

\section{Structural analysis and phase transformation}

With the purpose of examining phase transformations of zirconia for the various laser treated specimens, a X-ray diffractometer (Philips PW1710 series) using a continuous scan of $\mathrm{Cu} \mathrm{K}_{\alpha 1}$ radiation with $1.54056 \AA$ wavelength (and $\mathrm{Cu} \mathrm{K} \mathrm{K}_{\alpha 2}$ with $1.54439 \AA ; \mathrm{K}_{\alpha 2} / \mathrm{K}_{\alpha 1}=0.5$ ) was used to acquire the patterns within the $2 \theta$ range $20-80^{\circ}$ using a step size of $0.02^{\circ}$. 


\section{Results and Discussion}

\subsection{Surface morphology and microstructure}

From visual inspection, the coatings changed from a light gray to a soft yellow glassy transparent surface and spallation was not observed in any case.

SEM studies shows that a network of cracks has formed in the coatings, the porosity at the surface was eliminated and the homogeneity has been improved. Fig. 2 a shows a panoramic view of the surface of a laser-glazed coating in which some voids are noticeable at the surface, probably formed by release of gas in regions of higher porosity. These voids are located mostly over cracks. Fig. $2 b$ represents a closer view of a region in the same coating illustrating two types of cracks perpendicular to each other.

Previous studies focusing on the surface analysis of nanocomposite ceramic coatings [25] have reported the effectiveness of microtopography based in laser triangulation [24] by acquisition of information in relative large areas if compared with other methods. In this study, the same technique was employed so the coating surfaces could be inspected and roughness parameters determined. In order to minimize the influence of cracks on the roughness and hence obtain more accurate values, a non-standard method was applied to the profiles so the crack depth influence could be reduced. The calculated surface parameters are $R_{a}, R_{q}, R_{z}, R_{s k}$ and $R_{k u} . R_{a}$ represents the average surface roughness or average deviation, $R_{q}$ is the rms (root-mean-square) average or standard deviation, $R_{z}$ is a ten point height average, $R_{s k}$ or Skewness evaluates the symmetry of the profile about the mean line and $R_{k u}$ or Kurtosis is a measure of the randomness of profile heights above and below the mean line. $R_{a}$ and $R_{q}$ results, as shown in Fig. 3, demonstrate a significant decrease after laser-glazing. Disparity in roughness values of glazed coatings are related to the different laser glazing processing parameters. The as-acquired surface parameters suggest that coatings with higher crack density, as a consequence of the increase of scanning speed and overlap, present higher roughness values. However, specimen LG12 may present lower roughness than LG10 and LG7 due to the flatter surface caused by the largest overlap of tracks. By reducing the crack contribution on the analysed profiles, the surface roughness was decreased specially for coating LG10 (Fig. 3). In this case, LG5 maintained the lowest value which indicates, with no doubt, the less rough surface. The latter results are fairly supported by the profiles obtained by SEM (Fig. 10). Further work is necessary to better understand the contribution of both separated scanning speed and overlap on the surface profiles of the resolidified tracks.

The parameter $R_{z}$, representing the average height difference between the five highest peaks and the five lowest valleys, may also elucidate about the surface flatness, being for the glazed coatings not more than $30 \%$ of the as-sprayed value.

For all specimens, including the as-sprayed one, the parameter $R_{s k}$ is negative which indicates a predominance of valleys on the surface. $R_{k u}$ is 2.86 for the as-sprayed coating and substantially different for the others, representing the value 3 a perfectly random profile.

Fig. 4 depicts, on the left side, three-dimensional surface maps of coatings in the as-sprayed state and after laser-glazing. On the right side are secondary electron micrographs of the same surfaces. It is recognizable that a dissimilar morphology exists with substantial difference in roughness among the two specimens (note that the axis scale normal to the coating plane is considerably different for both maps). Fig. 4a represents the typical plasma-sprayed surface in which substantial incomplete melted particles and pores are identifiable and cause a very irregular profile. In the surface map of the glazed coating LG5 (Fig. 4b) (left) the axis normal to the coating plane is considerably magnified due to the very flat profile of the coating, this way, the direction of the laser beam passages can be seen.

The melted region, shown on Fig. 5, consists of a fully dense polyfaceted columnar microstructure differing significantly from the as-sprayed one. Despite the voids observed at the surface, pores have not been found within or at the lower region of the melted layer. Although the molten pool has solidified rapidly as the laser beam moved way, there was time enough for pores in the as-sprayed coating to coalesce and rise to the surface. The interface melted/HAZ (heat affected zone) seen on Fig. 5c, is very abrupt. It is clearly visible a well delimited columnar microstructure over a heat-affected lamellar microstructure that differs from the as-sprayed one (Fig. 5d). 


\subsection{Crack network and layer profile}

Fig. 6 depicts top view backscattered electron micrographs where there are recognizable crack networks with different crack densities for each specimen. The cracks tend to be oriented in two perpendicular directions, one along the laser beam moving direction (vertical in the micrographs) and the other perpendicular to it. The cracks oriented along the beam scan are spaced approximately at equal distance, coinciding with the edge of the subsequent track (Fig. 7). The other cracks, perpendicular to the laser moving direction are more dependent on the scanning speed, resulting in higher density of cracks with the increase of the scanning speed (Fig. 8).

The cracks are considered to be caused by shrinkage and relaxation of residual stresses during the cooling down of molten zirconia to room temperature [9,16,20,22]. The cracks are probably formed by the large and localized temperature gradients which generate residual stresses after the laser has passed. When the laser scanning speed is increased, the thermal gradient is higher and consequently the solidification is faster, resulting in higher thermal stresses and thus higher crack initiation.

Backscattered electron micrographs illustrating surface cracks distribution were all equalized and then modified by increasing drastically contrast (100\%) and brightness $(90 \%)$ so the cracks could be seen on a nearly white background. By means of an image analysis software, the post-treated backscattered electron micrographs were scanned and an average pixel intensity profile was drawn with the purpose of better illustrate the positioning of surface cracks along the beam travel direction (Fig. 9). Lower intensities represent darker regions (mostly cracks) on the surface. It is clearly visible a preferable location for the cracks, i.e. the overlapping region. The distance from each other is about the same as the corresponding to the chosen track shift (Table 2).

Different layer profiles were achieved by varying the applied energy and track overlap (Fig. 10). In all cases, the cracks across the densified layer are perpendicular to the surface and start to branch and deviate from the vertical direction bellow it within the porous PS coating. None of the coatings presented cracks extending to the interface between substrate and topcoat although LG5 seems to be quite damaged presenting very long cracks initiated at the overlapping region of the melted layer and extending across the PS coating to the centre of the tracks (Fig. 10a). Coating LG12 (Fig. 10d), shows the most uniform melted layer. The largest overlapping allied to smallest amount of irradiated energy generated a very dense layer of uniform thickness. Comparatively to the others, it presents the highest amount of vertical cracks regularly spaced but fewer and shorter branches across the plasma-sprayed coating.

For the different amounts of applied energy, the depth of the melted tracks, measured on single track specimens, ranged from approximately 70 to $175 \mu \mathrm{m}$ and track width from 1,01 to 1,21 mm (Fig. 11). For the whole laser-glazed coatings, the maximum layer thicknesses are within the values for the respective single track depth except for the LG12 coating that presented a slightly higher value, $77 \mu \mathrm{m}$, due to the high overlap (more than half of its respective track width: $0.61 \mathrm{~mm}$ ).

\subsection{Structural analysis and phase transformation}

The equilibrium phases of partially stabilized zirconia at room temperature are expected to be a low yttria content monoclinic phase and a high yttria content cubic phase. However, in the plasma spraying process, a non equilibrium tetragonal phase denoted as non-transformable $t$ ' phase arises due to rapid cooling of the coating during deposition [26].

The measured XRD spectra cover the $2 \theta$ range where the tetragonal, cubic and monoclinic main characteristic peaks of zirconia can be found (Fig. 12). It shows a polycrystalline tetragonal structure where the main diffraction peak is t'(111) for the as-sprayed, LG5 and LG7 coatings, and the t'(202) for LG10 and LG12. The $2 \theta$ range shown in Fig. 13 represents the range in which the most intense peaks of the monoclinic phase may appear if it is present. Only for the as-sprayed coating monoclinic zirconia exists. The as-sprayed coating exhibits mainly t' non-transformable tetragonal phase and a small amount of residual monoclinic phase deriving probably from partially melted particles with inhomogeneity in compositional distribution. The volume fraction of monoclinic phase was estimated to be approximately $3 \%$ calculated by the peak intensity ratio formula [27]: 


$$
\% m=\frac{I_{m(\overline{1} 11)}+I_{m(111)}}{I_{m(\overline{1} 11)}+I_{m(111)}+I_{t(111)}}
$$

where $I$ represents the diffraction intensity of the respective lattice planes.

All laser-glazed coatings present only t' non-transformable tetragonal phase, no monoclinic phase is visible. This can be explained by a homogenization, during melting, of the chemical composition of the two phases present in the as-sprayed coating. The cubic phase then formed, comprising the whole yttria content, transforms to the t' martensitic phase with the same composition by a diffusionless mechanism due to rapid cooling, increasing this way the solubility limit of the cubic phase stabilizer in the $\mathrm{ZrO}_{2}$ matrix [27]. Furthermore, detailed comparisons of the patterns on the range $72-76^{\circ}$ (Fig. 14), showed that the calculated lattice parameters of the t' phase do not vary more than $0,2 \%$. In all cases, the intensity of the peaks $t^{\prime}(002), t^{\prime}(113)$ and $t^{\prime}(004)$ increased strongly after the glazing process. The intensity of the main peak of the as-sprayed coating, $t^{\prime}(111)$, increased drastically for LG5, whereas decreased for the remaining coatings. These discrepancies in preferable crystal orientation are related to the different amounts of applied radiation and different cooling rates of the molten tracks.

Grain size and microstrain were also determined. Fitting a Pseudo-Voigt function on the main peaks of the XRD patterns it is possible to determine average grain size (Scherrer equation) and microstrain, from the Lorentzian and Gaussian components, respectively [28,29].

As expected, the largest average grain size is presented by the LG5 coating and decreases for those irradiated with lower energies (Fig.15). The relationship of the variation of microstrain with the specific energy density has an inverse behavior. In this case, the as-sprayed coating presents the largest value. 


\section{Conclusions}

Plasma-sprayed $\mathrm{ZrO}_{2}-8 \%$ wtY $\mathrm{O}_{3}$ thermal barrier coatings were subjected to a $\mathrm{CO}_{2}$ continuous wave laser glazing process in order to seal its surface porosity generating an external dense layer. For that, different amounts of radiation were applied to the specimens as well as different track overlapping. A morphological and microstructural characterization was accomplished resulting on the following conclusions:

- Plasma-sprayed TBCs presented a significant reduction of the surface roughness after laser-glazing.

- The melted layer has a fully dense polyfaceted columnar microstructure free from the microstructural inhomogeneities existing in the plasma-sprayed coatings. The interface melted/HAZ is found to be very abrupt.

- Controlled crack networks were achieved for each set of processing parameters. The crack networks are extremely dependent on the laser scanning speed and track overlapping. The density of cracks oriented perpendicularly to the laser moving direction increase with the increase of the laser scanning speed. The cracks oriented along the beam travel direction are located at the overlapping zone, coinciding with the edge of the subsequent track. In the range of the chosen laser scanning speeds and considering the very small beam diameter, the cracks along the beam travel direction are only dependent on the overlapping. All cracks within the melted layer are extended across its whole thickness.

- Laser-glazing allowed the homogenization of local inhomogeneities in $\mathrm{Y}_{2} \mathrm{O}_{3}$ content and led to the disappearance of the residual monoclinic phase due to rapid cooling. Only the non-transformable t' phase is present within the melted layers with some variations in preferable crystal orientation owed to different amounts of applied radiation and cooling rates.

- The variation of the laser irradiated energy resulted on grain sizes increasing from 26 to $52 \mathrm{~nm}$ as the energy increased. Microstrain behaved inversely. 


\section{Acknowledgments}

This work is part of the research project POCTI/CTM/44590/2002, approved by Portuguese Foundation for Science and Technology (FCT) and POCTI and supported by the European Community Fund FEDER.

The authors would like to thank Prof. Stöver, Dr. Vaßen and Dr. Buchkremer from the Institute for Materials and Processes in Energy Systems (IWV) in the Research Centre Jülich, Germany, for providing the necessary samples for this study. 


\section{References}

[1] R.A. Miller, J. Therm. Spray Technol. 6 (1997) 35-42.

[2] V. Teixeira, M. Andritschky, W. Fischer, H.P. Buchkremer, D. Stöver, Surf. Coat. Technol. 120121 (1999) 103-111.

[3] V. Teixeira, M. Andritschky, W. Fischer, H.P. Buchkremer, D. Stöver, J. Mater. Process. Technol. 92-93 (1999) 209-216.

[4] M. Lugovy, V. Slyunyayev, V. Teixeira, Surf. Coat. Technol. 184 (2004) 331-337.

[5] G. Antou, G. Montavon, F. Hlawka, A. Cornet, C. Coddet, F. Machi, Surf. Coat. Technol. 172 (2003) 279-290.

[6] K.C. Chang, W.J. Wei, C. Chen, Surf. Coat. Technol. 102 (1998) 197-204.

[7] P. Scardi, M. Leoni, Luca Bertamini, Thin Solid Films 278 (1996) 96-103.

[8] R.L. Jones, J. Therm. Spray Technol. 6 (1997) 77-84.

[9] H.L. Tsai, P.C. Tsai, Surf. Coat. Technol. 71 (1995) 53-59.

[10] P.C. Tsai, C.S. Hsu, Surf. Coat. Technol. 183 (2004) 29-34.

[11] S. Ahmaniemi., P. Vuoristo, T. Mäntylä, Mater. Sci. Eng. A366 (2004) 175-182.

[12] S. Ahmaniemi, M. Vippola, P. Vuoristo, T. Mäntylä, F. Cernuschi, L. Lutterotti, J. Europ. Ceram. Soc. 24 (2004) 2247-2258.

[13] S. Ahmaniemi, P. Vuoristo, T. Mäntylä, , Surf. Coat. Technol. 151-152 (2002) 412-417.

[14] J. Lawrence, L. Li, Surf. Coat. Technol. 162 (2002) 93-100.

[15] J.F. Li, L. Li, F.H. Stott, Int. J. Heat Mass Transfer 47 (2004) 1159-1174.

[16] S.O. Chwa, A. Ohmori, Surf. Coat. Technol. 153 (2002) 304-312.

[17] Z. Zhou, N.Eguchi, H. Shirasawa, and A. Ohmori, J. Therm. Spray Technol. 8(3) (1999) 405- 413.

[18] L. Pawlowski, J. Therm. Spray Technol. 8(2) (1999) 279-295.

[19] A.H. Wang, W.Y. Wang, C.S. Xie, W.L. Song, D.W. Zeng, Appl. Surf. Sci. 221 (2004) 293-301.

[20] L. Bradley, L. Li, F.H. Stott, Mater. Sci. Eng. A278 (2000) 204-212.

[21] L. Bradley, L. Li, F.H. Stott, Appl. Surf. Sci.138-139 (1999) 233-239.

[22] Y. Fu, A.W. Batchelor, H. Xing, Y. Gu, Wear 210 (1997) 157-164. 
[23] A. Portinha, V. Teixeira, J. Martins, M.F. Costa, R. Vaßen, D. Stöver, Advanced Research Workshop on Nanomaterials and Coatings, Kiev, NATO series E-Appl Sci., Kluwer Acad. Publ., 2002.

[24] M.F.M. Costa, Opt. Eng. 35(9) (1996) 2743-2747.

[25] A. Portinha, V. Teixeira, A. Monteiro, M.F. Costa, N. Lima, J. Martins and D. Martinez, Surf. Interface Anal. 35 (2003) 723-728.

[26] A.N. Khan, J. Lu, H. Liao, Mater. Sci. Eng. A359 (2003) 129-136.

[27] J. Moon, H. Choi, H. Kim, C. Lee, Surf. Coat. Technol. 155 (2002) 1-10.

[28] T.H. Keijser, J.I. Langford, E.J. Mittemeijer and A.B.P. Vogels, J. Appl. Cryst. 15 (1982) 308.

[29] F. Boulc'h, M.C. Schouler, P. Donnadieu, J.M. Chaix, E. Djurado, Image Anal. Stereol. 20 (2001) 157-161. 


\section{Figure captions}

Fig. 1. Schematic representation of beam guiding on the laser-glazing process.

Fig. 2. Secondary electron micrograph of the surface morphology of a laser-glazed coating: (a) panoramic view of the surface; (b) close view of cracks morphology, 1) crack across melted track, 2) crack on the overlapping region.

Fig. 3. Comparison of the surface roughness values $R a$ and $R q$ for the various coatings. On the left side are presented the original values and on the right side are the values for the glazed coatings after reducing crack effect.

Fig. 4. Three-dimensional maps (left), built from data acquired by the optical triangulation method, representing the surface of the as-sprayed coating (a) and the laser-glazed coating LG5 (b). Note that the axis scale normal to the coating plane is substantial different for both maps. The images on the right side are secondary electron micrographs of the corresponding surfaces on the left.

Fig 5. Fracture planes of the melted region of coating LG10, representing the microstructure variation from the surface to the bottom; (a) surface morphology of the polyfaceted columnar microstructure, b) cross-sectional view of the columnar melted region, (c) interfacial region, (d) plasma-sprayed heatunaffected region.

Fig. 6. Representative backscattered electron micrographs of the surface of the glazed coatings illustrating crack distribution; (a) LG5, (b) LG7, (c) LG10, (d) LG12.

Fig. 7. Schematic micrograph illustrating the location of initiation of cracks along the beam travel direction.

Fig. 8. Electron micrograph of single tracks showing different crack density for the various scanning speeds; (a) $12000 \mathrm{~mm} / \mathrm{min}$, (b) $10000 \mathrm{~mm} / \mathrm{min}$, (c) $7000 \mathrm{~mm} / \mathrm{min}$.

Fig. 9. Pixel intensity profile of the direction perpendicular to the beam travel; (a) LG5, (b) LG7, (c) LG10, (d) LG12. Lower intensities represent darker regions (mostly cracks) on the surface. Post-treated backscattered electron micrographs were scanned by means of an image analysis software and a pixel intensity profile was drawn with the purpose of better illustrate the location of surface cracks along the beam travel direction.

Fig. 10. Cross-sectional backscattered electron micrographs of the plane perpendicular to the beam travel direction illustrating the various layer profiles and segmented cracks for the various coatings; (a) LG5, (b) LG7, (c) LG10, (d) LG12.

Fig. 11. Variation of track depth and width with the applied laser beam energy, for a single track.

Fig. 12. XRD spectra in the entire range; (a) as-sprayed, (b) LG5, (c) LG7, (d) LG10, (e) LG12.

Fig. 13. XRD spectra in the low $2 \theta$ range; (a) as-sprayed, (b) LG5, (c) LG7, (d) LG10, (e) LG12.

Fig. 14. XRD spectra in the high $2 \theta$ range; (a) as-sprayed, (b) LG5, (c) LG7, (d) LG10, (e) LG12.

Fig. 15. Variation of the grain size and microstrain with the applied laser beam energy. 
Tables

Table 1: Laser system characteristics and processing parameters

\begin{tabular}{ll}
\hline TEM Mode & $01^{*}$ \\
Raw beam size $(\mathrm{mm})$ & 20 \\
Focal length $(\mathrm{mm})$ & 150 \\
Wave type & Continuous \\
Glazing beam diameter $(\mathrm{mm})$ & 0.43 \\
Power $(\mathrm{W})$ & 500 \\
\hline
\end{tabular}

Table 2: Varied parameters and resultant conditions

\begin{tabular}{ccccc}
\hline Specimen & $\begin{array}{c}\text { Scanning speed } \\
(\mathrm{mm} / \mathrm{min})\end{array}$ & $\begin{array}{c}\text { Track shift } \\
(\mathrm{mm})\end{array}$ & $\begin{array}{c}\text { Overlap } \\
(\mathrm{mm})\end{array}$ & $\begin{array}{c}\text { Energy density } \\
\left(\mathrm{J} / \mathrm{mm}^{2}\right)\end{array}$ \\
\hline LG5 & 5000 & 1 & 0.21 & 14.0 \\
LG7 & 7000 & 0.7 & 0.40 & 10.0 \\
LG10 & 10000 & 0.5 & 0.56 & 7.0 \\
LG12 & 12000 & 0.4 & 0.61 & 5.8 \\
\hline
\end{tabular}




\section{Figures}

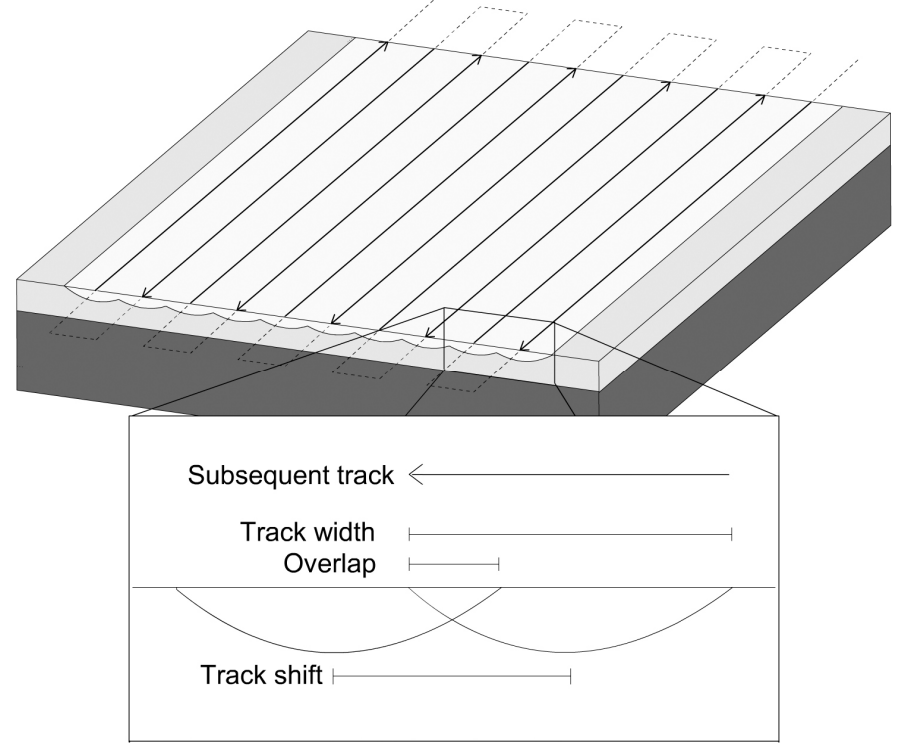

Fig.1

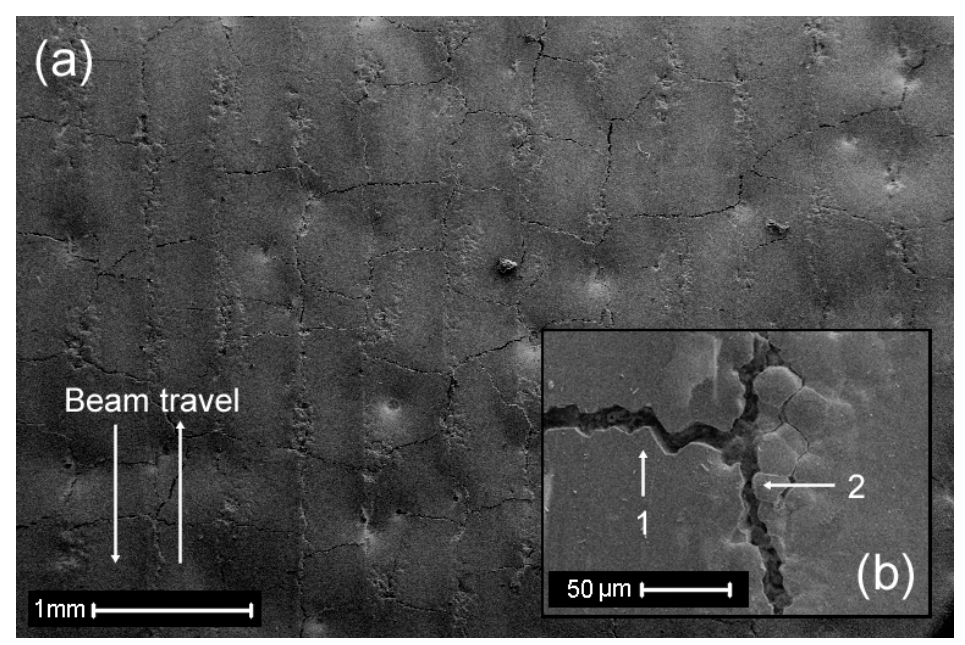

Fig. 2

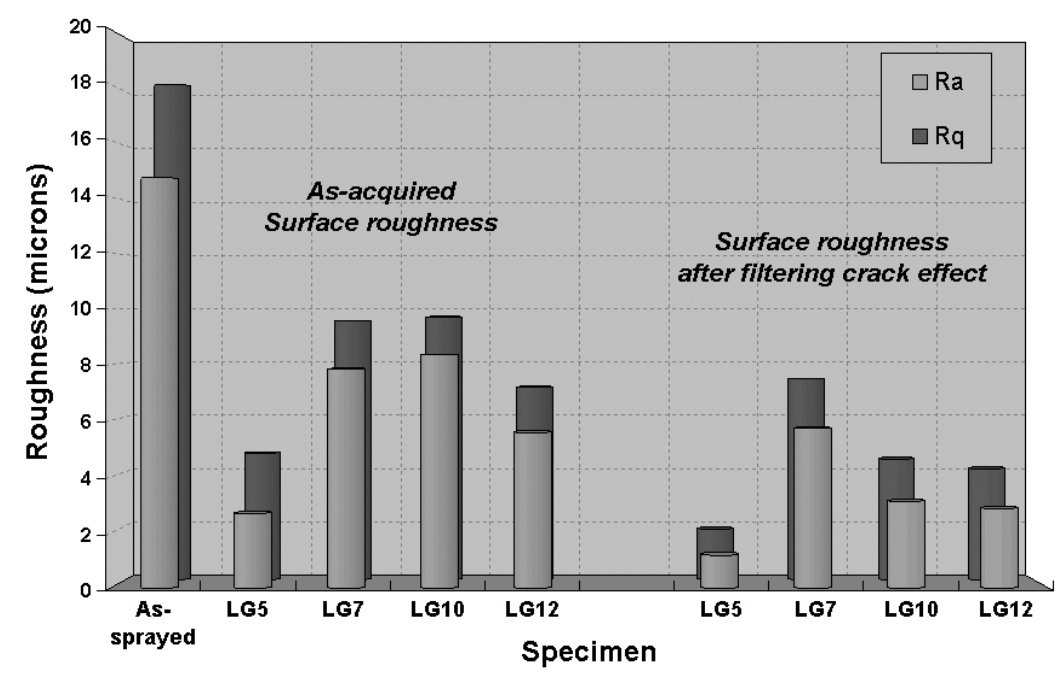

Fig. 3 

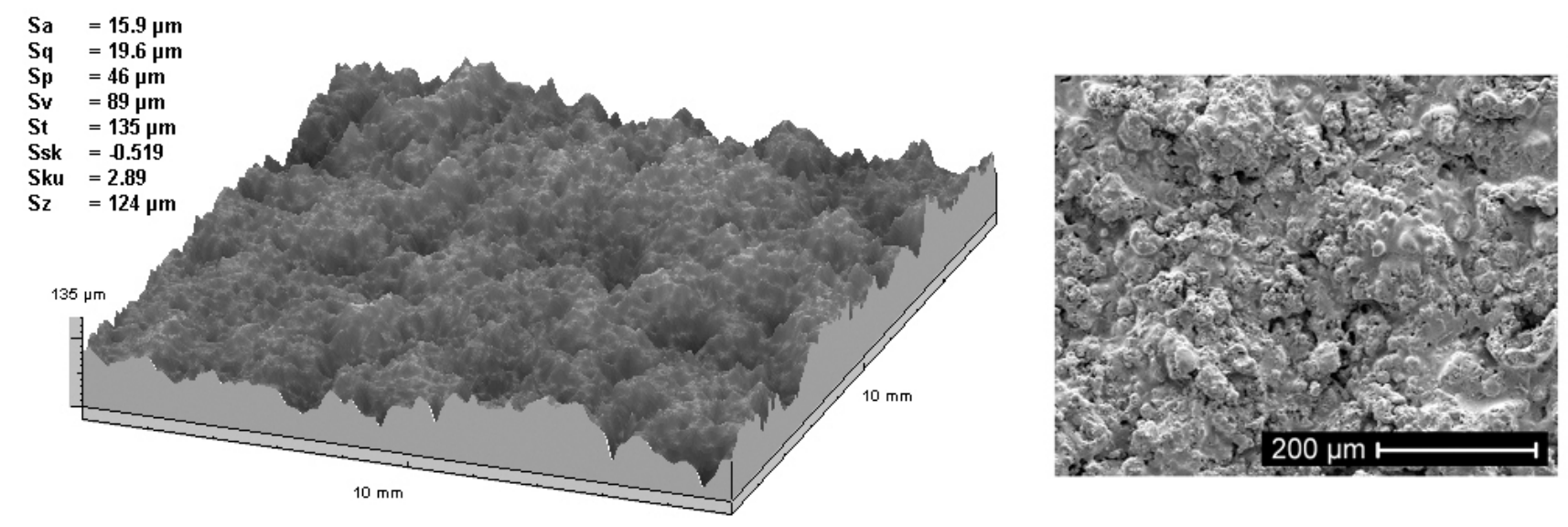

(a)

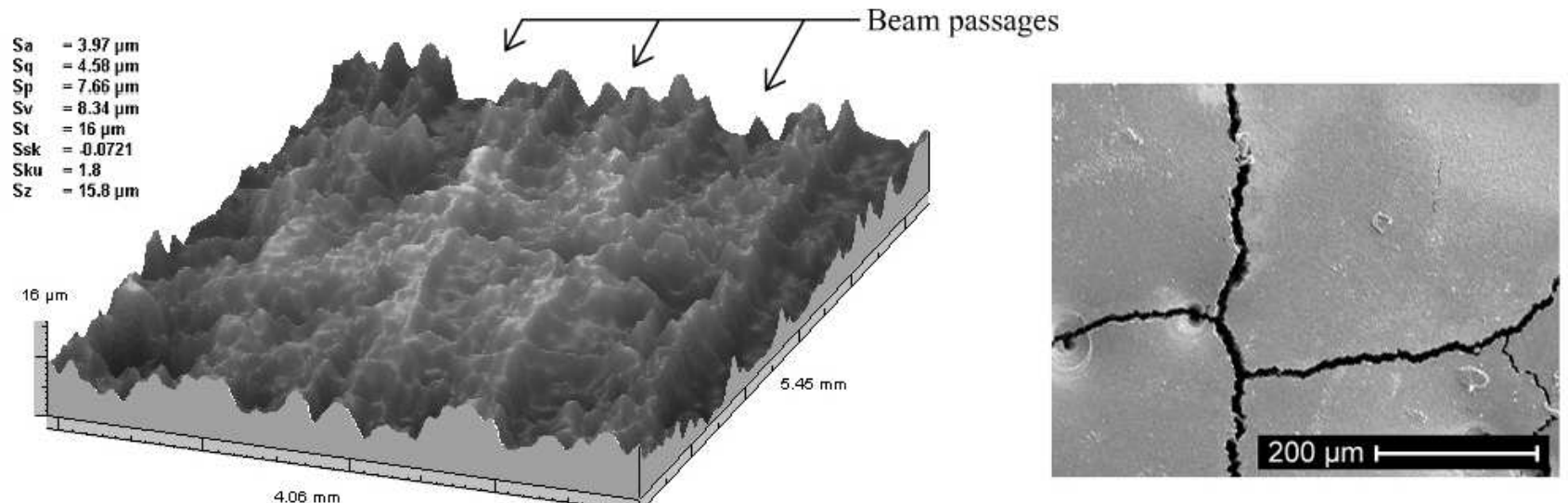

(b)

Fig. 4
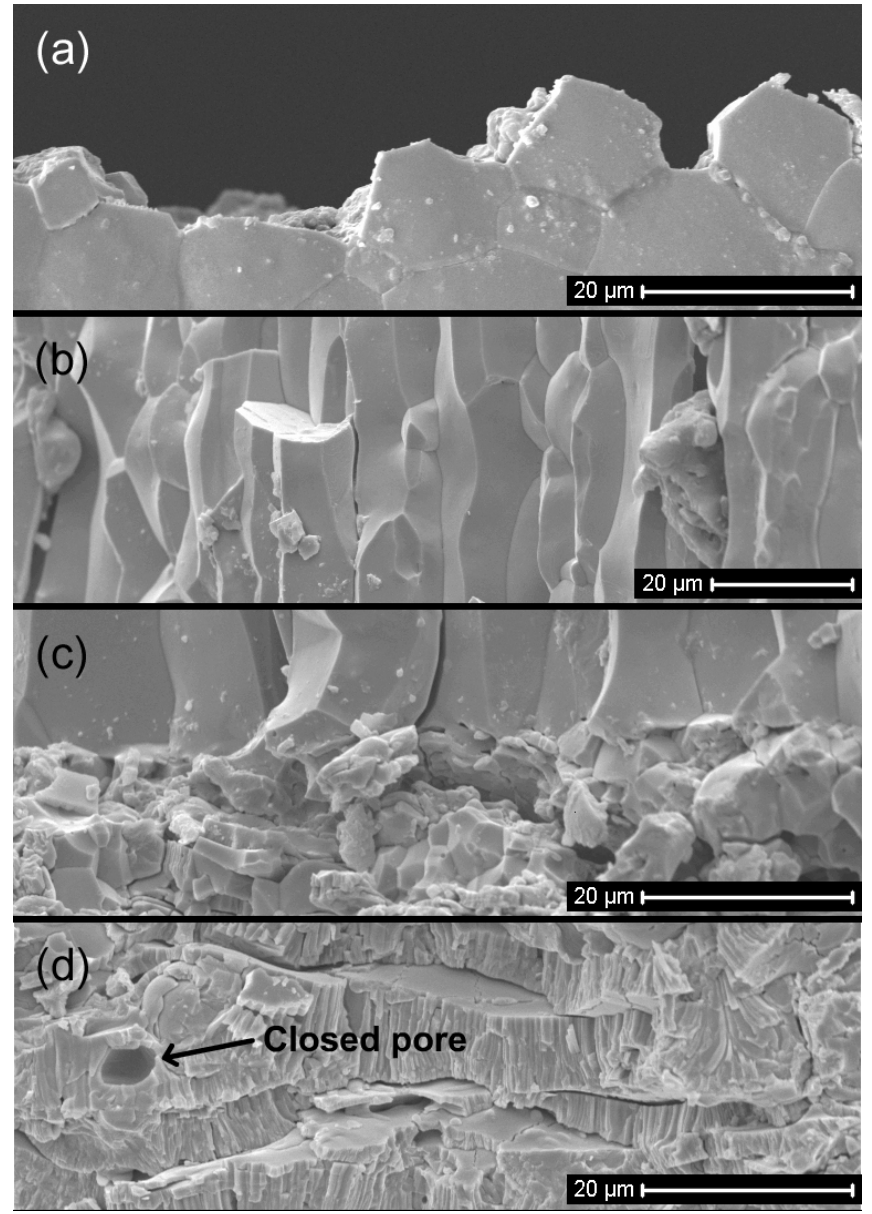

Fig. 5 

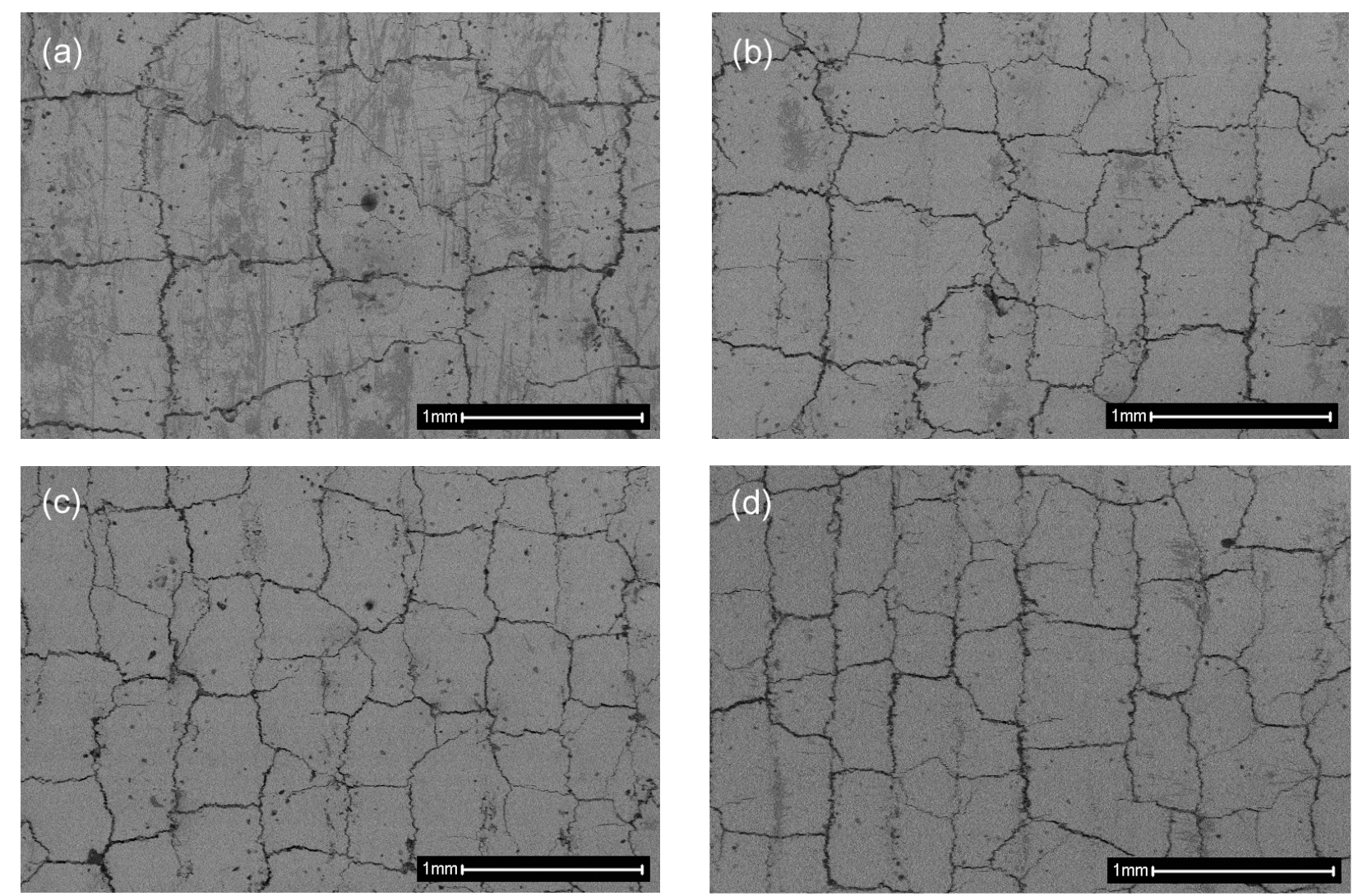

Fig. 6

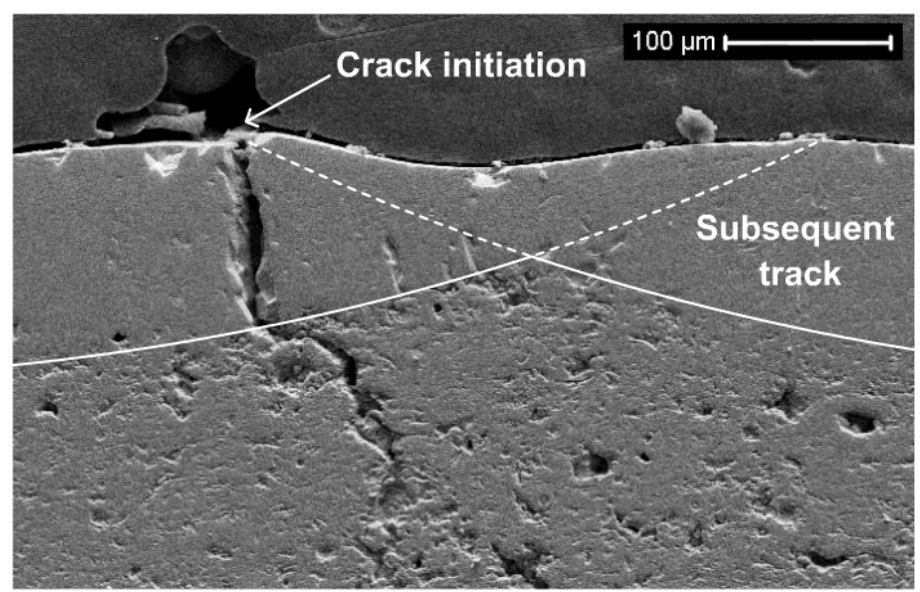

Fig. 7

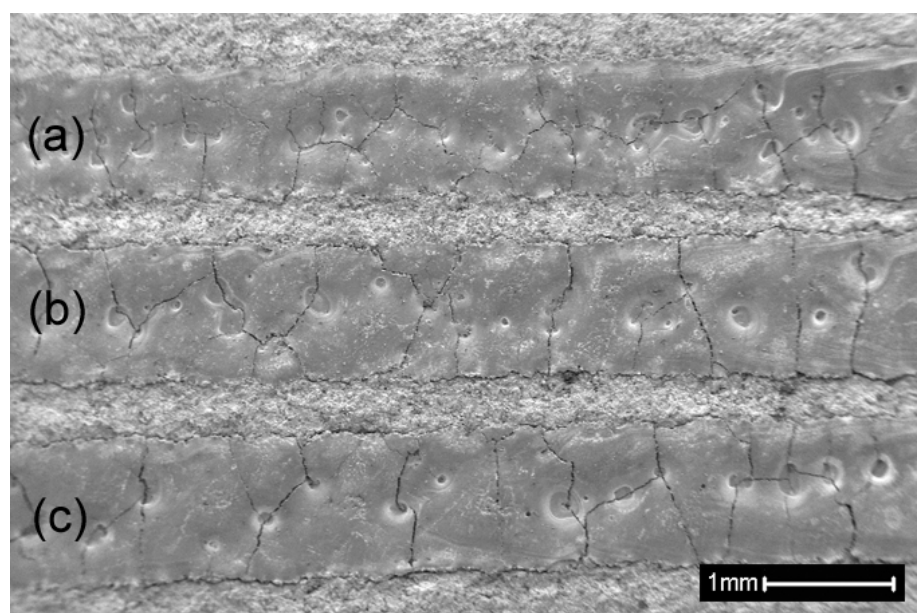

Fig. 8 

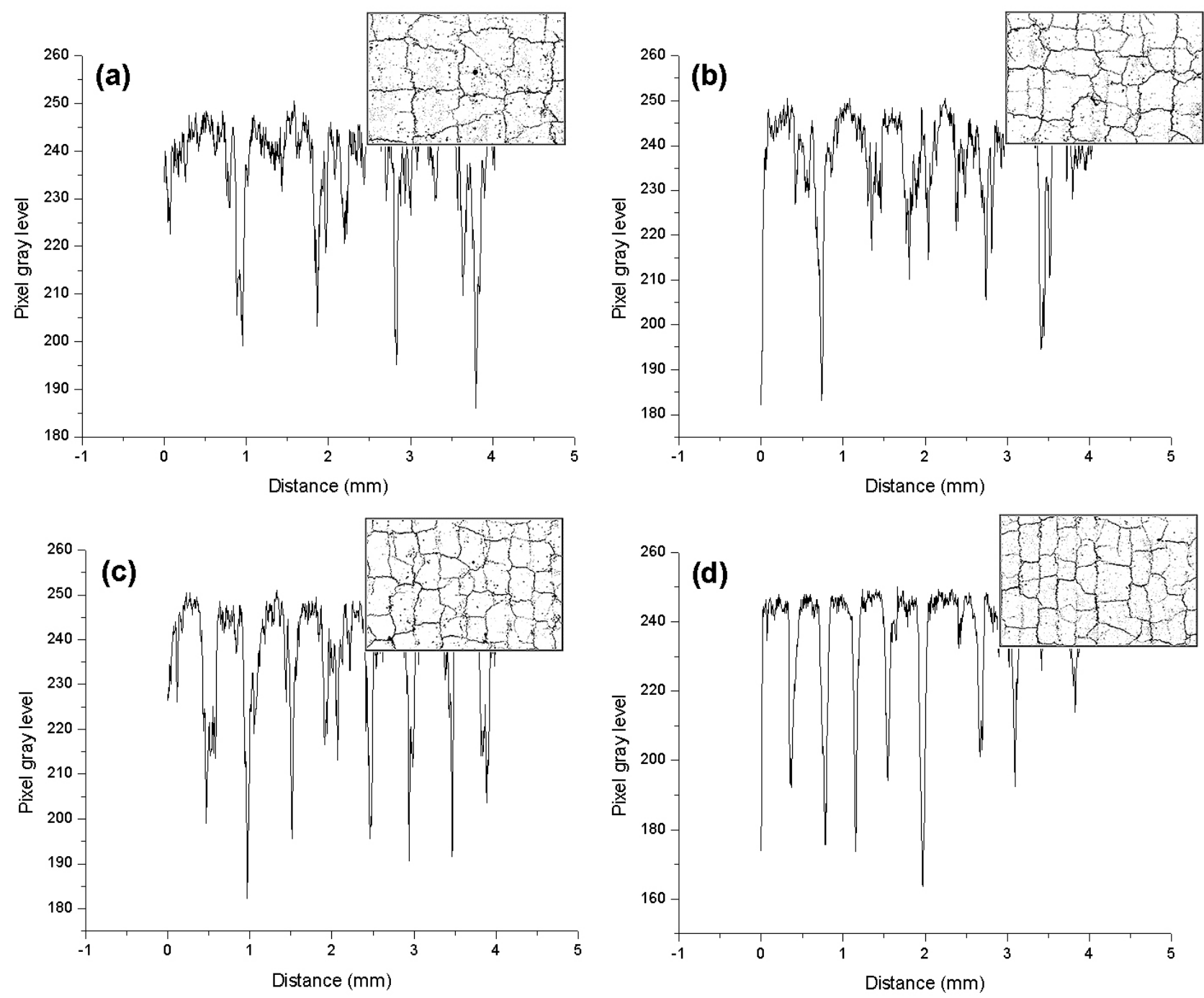

Fig. 9
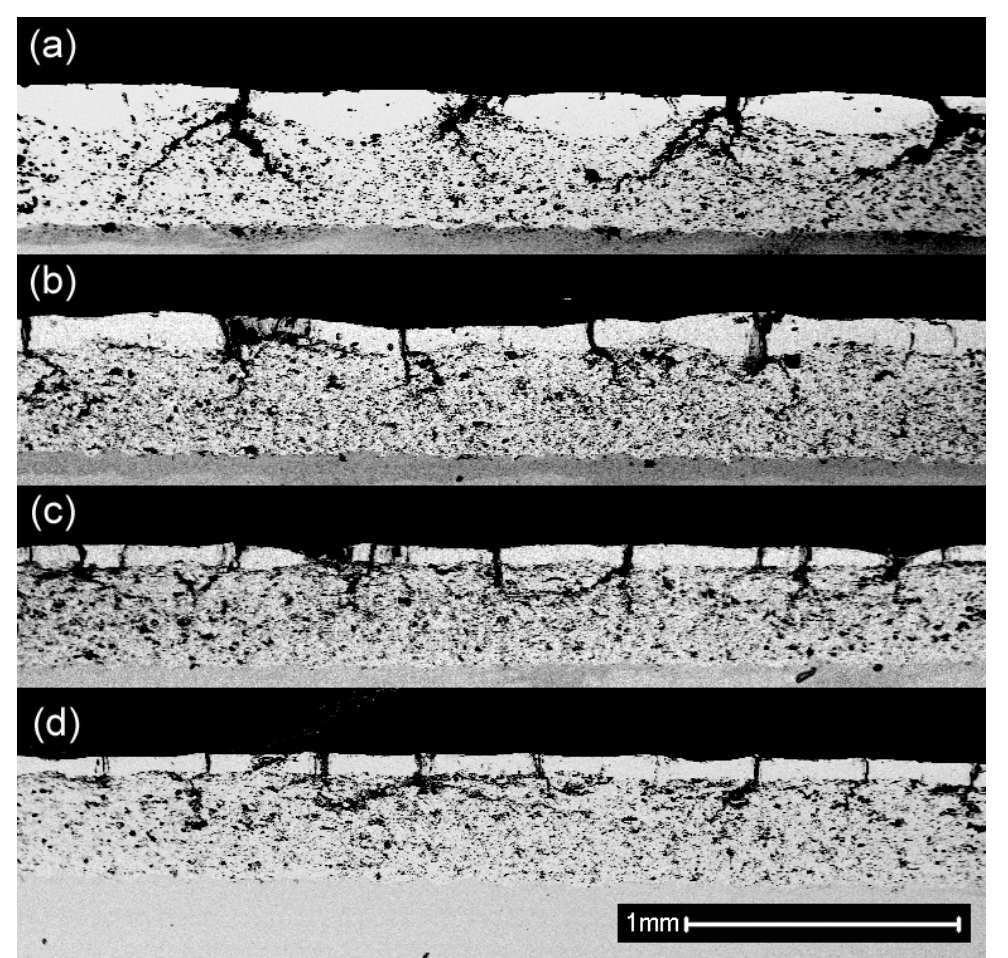

Fig. 10 


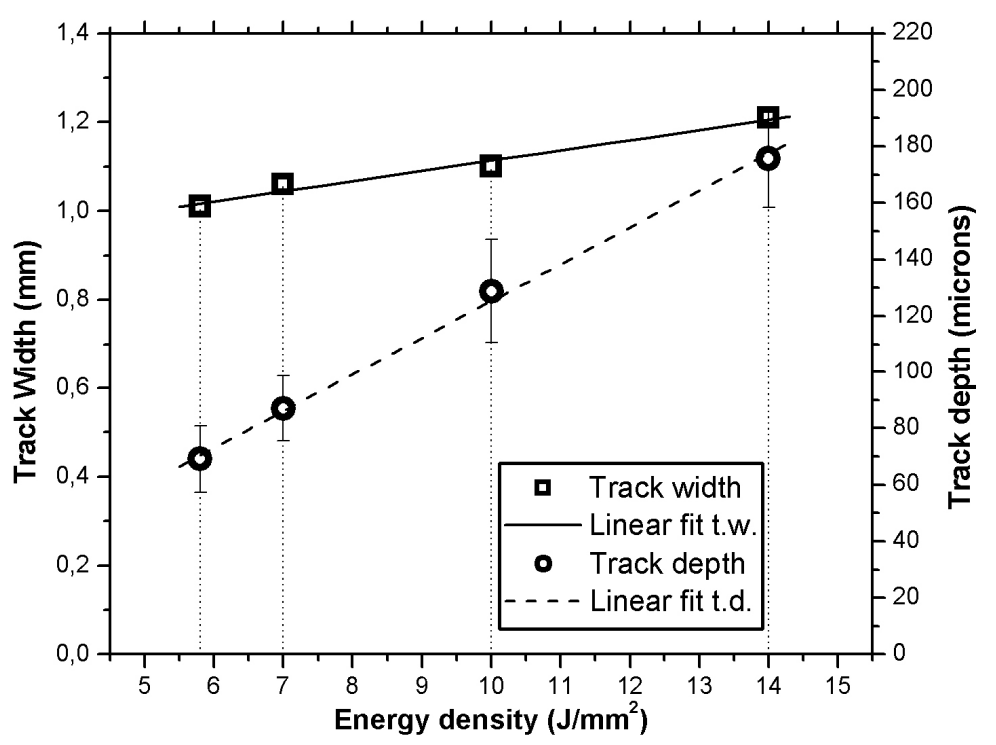

Fig. 11

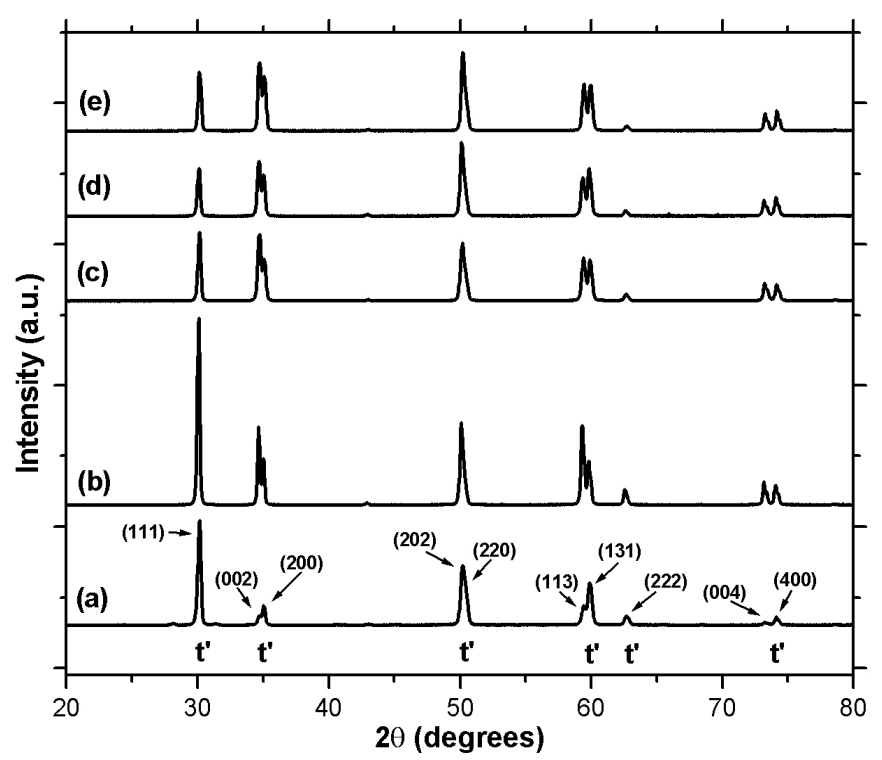

Fig. 12

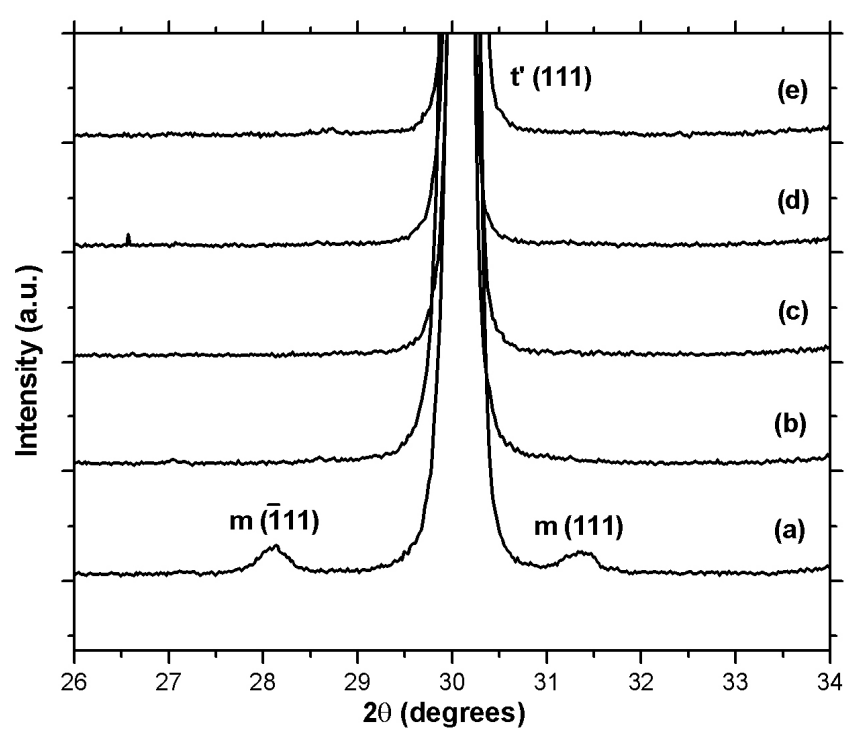

Fig. 13 


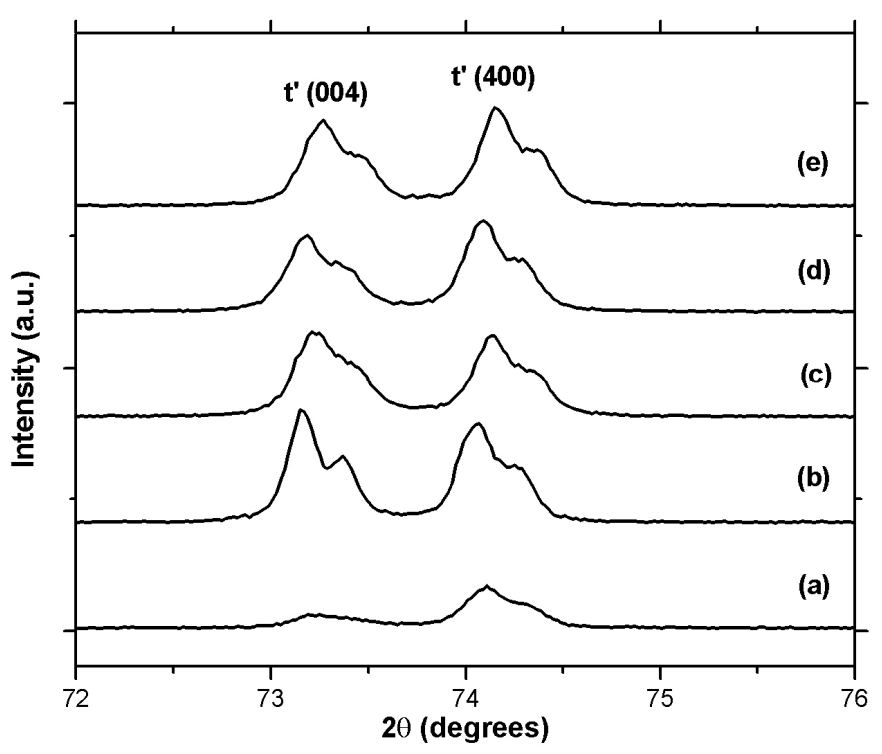

Fig. 14

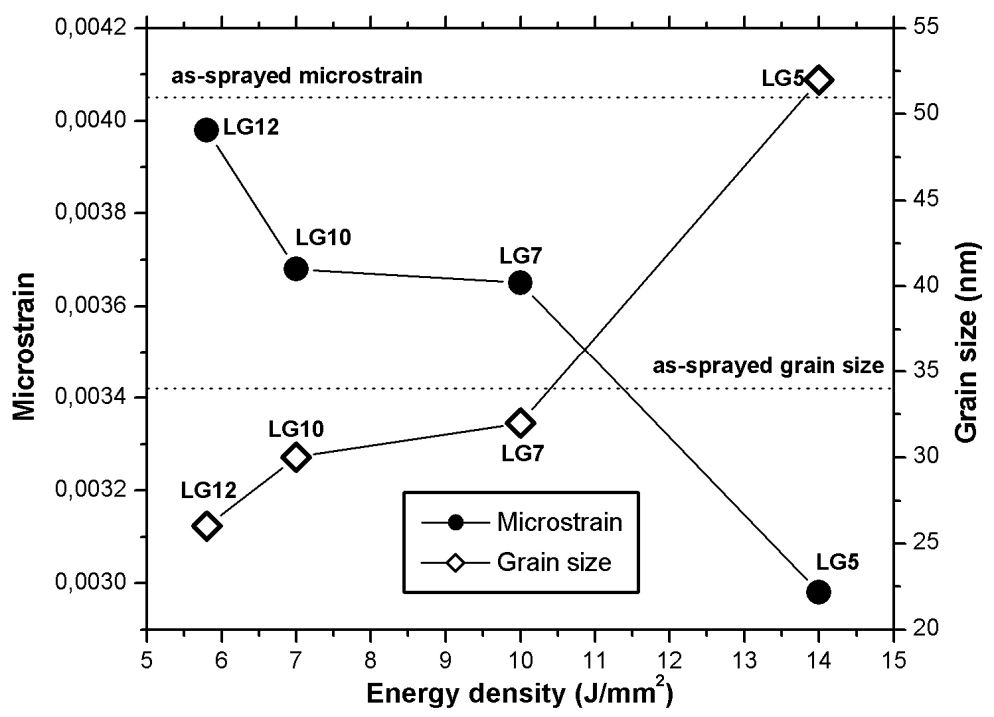

Fig. 15 